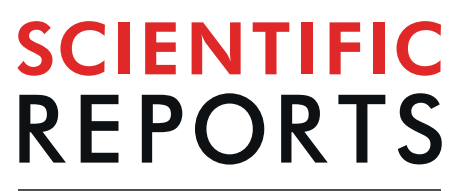

natureresearch

\title{
Investigation of the cause of reduced sugar content in Kiyomi tangor fruit of Ziyang xiangcheng (Citrus junos Sieb. ex Tanaka) rootstock
}

\author{
Tiantian Dong $\mathbb{1}^{1,4}$, Bo Xiong $\mathbb{1}^{1,4}$, Shengjia Huang ${ }^{1}$, Ling Liao ${ }^{1}$, Xia Qiu ${ }^{1}$, Guochao Sun ${ }^{1,2}$, \\ Yunzhenzi He${ }^{1}$, Changwen Duan ${ }^{1}$, Xiaojia Wang ${ }^{1}$, Xu Zhang ${ }^{1}$, Sichen $\mathrm{Li}^{1}$, Jin Zhu ${ }^{3}$ \& \\ Zhihui Wang ${ }^{1,2^{*}}$
}

Ziyang xiangcheng (Citrus junos Sieb. ex Tanaka) (Cj) rootstock is effective in Citrus production; however, when Cj rootstock was used, sugar content in Kiyomi tangor fruit was significantly lower than that in the fruit produced using Poncirus trifoliata (L.) Raf. rootstock (Pt). Therefore, using $K$. tangor, we explored the cause of this difference, determining sugar accumulation, sucrose-metabolism enzyme activities, and gene expression. Before ripening, sugar content in fruits with $\mathrm{Cj}$ rootstock was significantly lower than that in fruits with Pt rootstock, due to low fructose and sucrose content. Sucrose phosphate synthase (SPS) activity of Pt was higher than that of $C j$ in the early growth stage (at 90-210 days after anthesis), however it was opposite at 240-300 days after anthesis. Additionally, neutral invertase ( $\mathrm{NI}$ ) activity of $\mathrm{Pt}$ was higher than that of $\mathrm{Cj}$. Gene expression in Pt was higher than that in $\mathrm{Cj}$, but is was essentially the same at maturity. SPS and NI activities and CitSPS1 expression were positively correlated with sucrose, fructose, and glucose content, but CSCW1 expression was negatively correlated with the sugars. Overall, the weak flavour of $K$. tangor fruit with $\mathrm{Cj}$ rootstock was regulated by the sucrose metabolism-related enzymes and gene expression.

Citrus is a commercially important genus of the Rutaceae family and comprises fruit species that are cultivated globally ${ }^{1,2}$. Kiyomi tangor (Citrus unshiu Marcov. forma miyagawawase $\times$ Citrus sinensis Osbeck) is the first orange hybrid bred using the Satsuma mandarin (Citrus unshiu Marcov. forma miyagawawase) and the Trovita orange (Citrus sinensis Osbeck) in Japan ${ }^{3}$. Kiyomi tangor (K. tangor)fruits ripen during the off-season; it is therefore an off-season fruit in the Citrus market, and its prospect is very promising ${ }^{4}$. Trifoliate orange (Poncirus trifoliata (L.) Raf.) (Pt) is the most common rootstock used for Citrus production because it is resistant to cold and foot rot ${ }^{5}$. However, when $K$. tangor was grafted on Pt rootstock and planted in alkaline soil, the hindered absorption of trace mineral elements led to the element deficiency disease ${ }^{6}$.

Citrus production is affected by many environmental factors including drought, salt, alkali and extreme temperature ${ }^{7}$. Grafting is one of the most effective technique for enhancing citrus reproduction and thus production. Rootstock is an important part of the Citrus industry as it influences scion characteristics such as fruit quality, canopy size, and resistance ${ }^{8,9}$. Previous studies have demonstrated that Citrus-grafted seedlings with $\mathrm{Pt}$ as rootstock were prone to nutrient deficiency and growth retardation in calcareous soils ${ }^{10,11}$. However, Ziyang xiangcheng (Citrus junos Sieb. ex Tanaka) $(\mathrm{Cj})$ is a local Citrus rootstock originating from Southwest China with excellent disease-, alkali-, drought-, and cold-resistant characteristics ${ }^{10}$. Additionally, $\mathrm{Cj}$ is more alkali-resistant than Pt. Moreover, It was not until the soil $\mathrm{pH}$ increased to 8.3 that the leaf etiolation appeared on Citrus with $\mathrm{Cj}$ as rootstock ${ }^{12}$. Therefore, in recent years, $\mathrm{Cj}$ has been used as a rootstock in more and more scion varieties in

${ }^{1}$ College of Horticulture, Sichuan Agricultural University, Chengdu, 611130, Sichuan, China. ${ }^{2}$ Institute of Pomology and Olericulture, Sichuan Agricultural University, Chengdu, 611130, Sichuan, China. ${ }^{3}$ Sichuan Horticultural Crop Extension Station, 610041, Sichuan, China. ${ }^{4}$ These authors contributed equally: Tiantian Dong and Bo Xiong. *email: wangzhihui318@126.com 


\begin{tabular}{|l|l|l|l|}
\hline $\begin{array}{l}\text { Sugar } \\
\text { component }\end{array}$ & $\begin{array}{l}\text { Regression equations } \\
\left(\mathbf{m g} \cdot \mathbf{m L}^{-1}\right)\end{array}$ & $\begin{array}{l}\text { Linearity range } \\
\left(\mathbf{m g} \cdot \mathbf{m L}^{-1}\right)\end{array}$ & $\begin{array}{l}\text { Correlation } \\
\text { coefficients }\end{array}$ \\
\hline Sucrose & $\mathrm{y}=183447 \mathrm{x}+29368$ & $0.04 \sim 5$ & 0.9998 \\
\hline Fructose & $\mathrm{y}=173173 \mathrm{x}+1064.6$ & $0.04 \sim 5$ & 0.9996 \\
\hline Glucose & $\mathrm{y}=189541 \mathrm{x}+7625.5$ & $0.04 \sim 5$ & 0.9996 \\
\hline
\end{tabular}

Table 1. Regression equations, correlation coefficients, and linearity range of sugar components.

\begin{tabular}{|l|l|l|l|l|}
\hline $\begin{array}{l}\text { Sugar } \\
\text { component }\end{array}$ & Precision \% & Repeatability \% & Stability \% & Percent recovery \% \\
\hline Sucrose & 0.7155 & 2.0058 & 2.2624 & 102.3663 \\
\hline Fructose & 3.1155 & 0.9492 & 1.5724 & 99.6536 \\
\hline Glucose & 2.0498 & 3.0342 & 1.1107 & 109.8767 \\
\hline
\end{tabular}

Table 2. Precision, repeatability, stability, and percent recovery RSD of this method. RSD (\%) = relative standard deviation.

China due to its excellent tolerance to alkaline stress and iron deficiency ${ }^{10}$. However, we found that the sugar content of $K$. tangor fruit with $\mathrm{Cj}$ as rootstock was lower than that of $\mathrm{Pt}$ in the field experiment.

The ripening process of citrus fruits is usually accompanied by the accumulation of sugars and the degradation of organic acids ${ }^{13}$. Sugar, which is mainly in the form of sucrose, fructose, and glucose, plays an key role in the quality and flavour, and the differences in sugar content determine the sweetness and colour of fruit ${ }^{14,15}$. Sucrose is the key determinant of yield, accounting for approximately $90 \%$ of the carbohydrates in plants ${ }^{16}$. By changing the activity balance of sucrose phosphate synthase (SPS) and sucrose synthase (SS), sucrose metabolism enzymes regulate the decomposition and synthesis of sucrose and realise the redistribution of carbohydrates ${ }^{17,18}$.

Among the enzymes involved in sucrose metabolism, SS and invertase (INVs) are involved in the cleavage of sucrose, while SPS catalyses the synthesis of sucrose ${ }^{19}$. Sucrose phosphate synthase, which is regulated by metabolites and reversible protein phosphorylation in plant tissues and promoted by glucose-6-phosphate, acts on UDP-glucose and fructose-6-phosphate to produce sucrose-phosphate in the sucrose biosynthesis pathway ${ }^{20,21}$. SS is widely regarded as a key enzyme involved in sucrose metabolism, which may play an important role in carbon distribution in sugar synthesis, sucrose conversion, and adenosine preservation of the respiratory pathways $^{22,23}$. SS participates in the process degradation of sucrose to UDP-glucose and fructose ${ }^{21}$. Sucrose synthase has bidirectional function, the direction of sucrose cleavage (SS-I) and the direction of sucrose synthesis (SS-II) ${ }^{22}$. INVs is important for carbohydrate supply to sink tissues; they play a key role in regulating, amplifying, and integrating different signals, which leads to the transportation of the end product of photosynthesis from source to $\operatorname{sink}^{22,24}$. INVs act on sucrose to form glucose and fructose $\mathrm{e}^{21,25}$. There are two main groups of INVs in plants, namely acidic invertase (AI) and neutral invertase $(\mathrm{NI})^{26}$, which play a role under different $\mathrm{pH}$ conditions ${ }^{23,27}$. Several studies have reported the correlation between sugar content and metabolism enzyme activity in mature fruit and that sucrose-metabolism enzymes play an important role in sugar metabolism ${ }^{28,29}$.

Sucrose accumulation in fruit is related to gene expression of sucrose-metabolism enzymes ${ }^{30}$. In recent years, sugar metabolism-related genes were cloned in Citrus including the sucrose synthesis directional genes (CitSPS1, CitSPS2, CitSUS $)^{31,32}$, sucrose cleavage directional genes $(C S C W 1, C U A I 1)^{33,34}$, acid invertase gene $(C i t A I)^{35}$, and neutral invertase gene $(N I N)^{36}$. Although there are many studies regarding sugar metabolism, enzyme activity, and gene expression in Citrus fruits, the molecular mechanism underlying the reduction in fruit sugar content in $K$. tangor grafted onto $\mathrm{Cj}$ rootstock has rarely been elucidated. To investigate the cause of this reduction, we compared $K$. tangor fruit of $\mathrm{Cj}$ with that of $\mathrm{Pt}$ and analysed the effect of $\mathrm{Cj}$ rootstock on sugar accumulation in $K$. tangor fruit at the physiological and molecular levels in the present study.

\section{Results}

Investigation of the HPLC method. There was a strong linear relationship between the concentration of each standard solution and the peak area; the correlation coefficient was 0.9996-0.9998, which indicates high accuracy (Table 1 ). The linearity range of the standard curve was $0.04-5 \mathrm{mg} \cdot \mathrm{mL}^{-1}$, which satisfied the detection and analysis of conditions of each sugar component.

The RSD values of each standard solution were $0.72-3.12 \%$ (Table 2 ). The RSD values of the three carbohydrates ranged from $0.9492 \%$ to $3.03 \%$. The RSD values of the sugar content in the solution at different times were less than $2.26 \%$, indicating that the solution was stable within $72 \mathrm{~h}$. The average recoveries were $99.65-109.88 \%$ and RSD values were less than $2.90 \%$ (Table 2). The results showed that the method had high precision, repeatability, stability, and percent recovery.

In the present study, a HPLC method was developed to analyse the content of the sugar components. The chromatograms of sucrose, fructose, and glucose standards are shown in Fig. 1. Based on the peak type and retention time, the three sugar components were adequately separated within $14 \mathrm{~min}$.

Effect of different rootstocks on sugar and acid content in $K$. tangor fruit. Different rootstocks significantly influenced $K$. tangor sugar content. The total sugar(TS) content in $K$. tangor fruit showed regular 


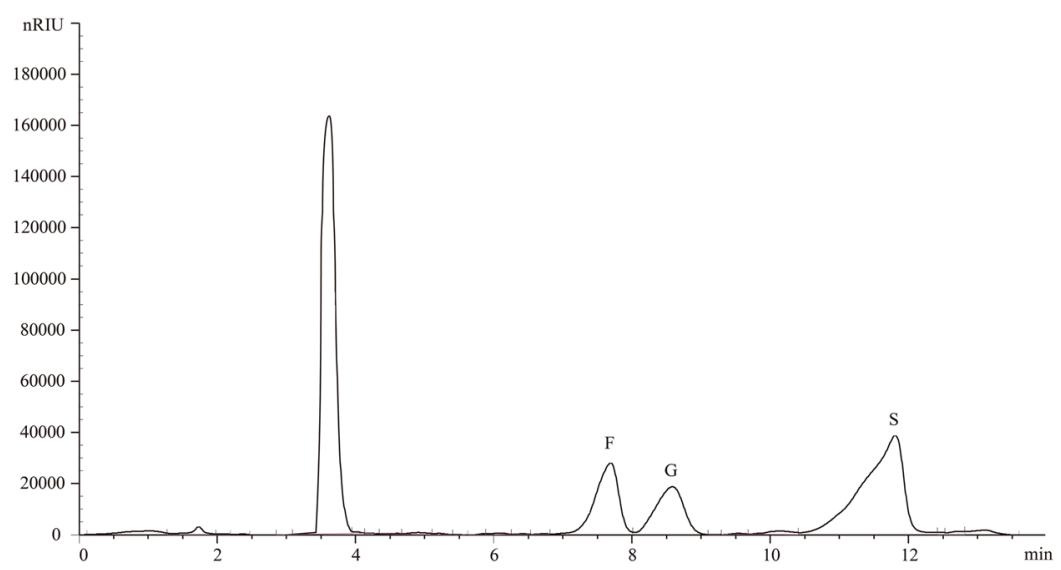

Figure 1. High Performance Liquid Chromatography detection of sugar components in the standard sample. Fructose, glucose, and sucrose followed the peak sequence

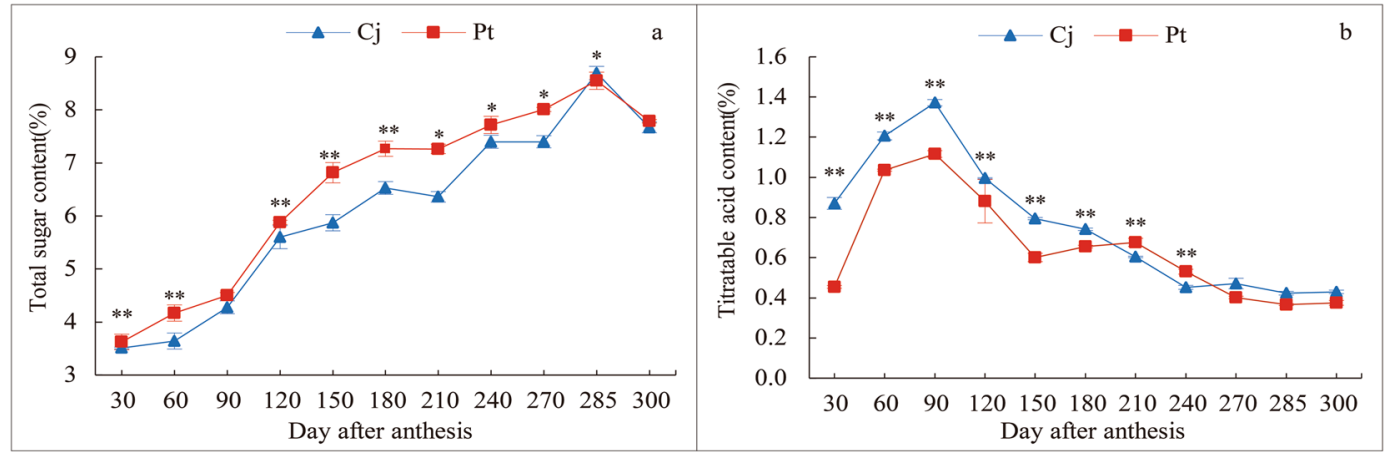

Figure 2. Sugar and acid content in K. tangor fruits of different rootstocks. (a) Total sugar content, (b) Titratable acid content. The vertical bars represent standard error. *Shows significant differences $(p<0.05)$ and **shows extremely significant differences $(\mathrm{p}<0.01)$ between $\mathrm{Pt}$ and $\mathrm{Cj}$.

changes during growth and development, increasing continuously at 30-285 days after anthesis and decreasing slightly at 300 days after anthesis. The TS of $\mathrm{Cj}$ was always lower than that of Pt prior to 285 days after anthesis. The titratable acid(TA) content increased at 30-90 days after anthesis and decreased slowly at 90 days after anthesis. Additionally, prior to 210 days after anthesis, the TA content of $\mathrm{Cj}$ was always higher than that of Pt. However, there was no significant difference in TA content in fruits at the ripening stage (270-300 days after anthesis) (Fig. 2).

Effect of different rootstocks on the sugar components in $\boldsymbol{K}$. tangor fruit. The results showed that the sugars in $K$. tangor fruit mainly consist of the accumulated sucrose type and that the sucrose content was more than two times higher than the fructose and glucose content in the later stage of fruit development. Additionally, during fruit growth and development, the sugar components showed an increasing trend. The sucrose content in both rootstocks increased steadily before reaching 270 days after-anthesis (Fig. 3a). The sucrose content of Pt was always higher than that of $\mathrm{Cj}$ after reaching 120 days after-anthesis (Fig. 3a). Fructose content increased initially, and then remained stable after reaching 180 days after anthesis (Fig. 3b). The glucose content increased rapidly at first, increased slowly from 120 to 180 days after anthesis, decreased slightly from 180 to 210 days after anthesis, and then remained nearly unchanged (Fig. 3c). The fructose and glucose content of Pt was always higher than that of $\mathrm{Cj}$ (Fig. 3b,c).

Effect of different rootstocks on sucrose-metabolism enzyme activities in $\boldsymbol{K}$. tangor fruit. The SPS activity remained essentially unchanged before fruit ripening and increased rapidly after reaching 270 days after anthesis. The SPS activity of Pt was initially lower than that of $\mathrm{Cj}$, higher than that of $\mathrm{Cj}$ at 90 to 210 days after anthesis, then lower than that of $\mathrm{Cj}$ at 240 to 300 days after anthesis (Fig. 4a). The change regularity of SS-I activity in the two rootstocks differed. For example, 30-180 days after anthesis, the SS-I activity of Pt was significantly higher than that of Cj (Fig. 4b). The SS-II activity changed regularly throughout fruit growth and development. The SS-II activity increased slowly and then rapidly, reached its maximum at 240 days after anthesis, and then decreased (Fig. 4c). The SS-II activity of Pt was always lower than that of Cj, except at 30-60 and 300 days after anthesis (Fig. 4c). The AI activity increased rapidly at 180 days after anthesis and then decreased slowly at 210 days (Fig. $4 \mathrm{~d}$ ). The AI activity of Pt was always lower than that of Cj, except at 285 days after anthesis (Fig. $4 \mathrm{~d}$ ). The 

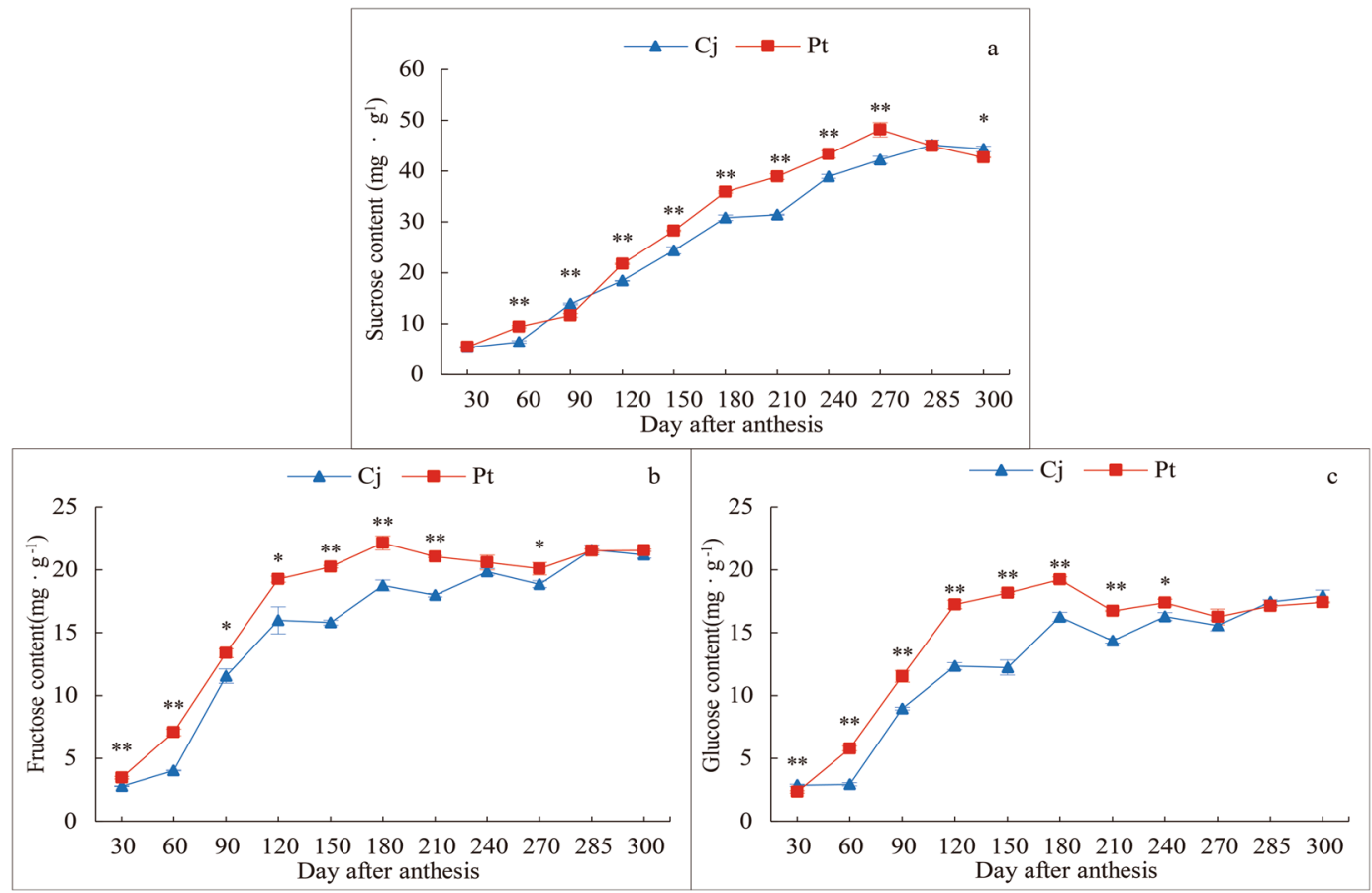

Figure 3. Content of sugar components in K. tangor fruits of different rootstocks. (a) Sucrose content, (b) Fructose content, (c) Glucose content. The vertical bars represent standard error. *Shows significant differences $(\mathrm{p}<0.05)$ and $* *$ shows extremely significant differences $(\mathrm{p}<0.01)$ between Pt and Cj.

NI activity of Pt reached its maximum at 210 days after anthesis, whereas that in $\mathrm{Cj}$ reached its maximum at 240 days after anthesis. The NI activity then decreased slowly (240-300 days after anthesis), and the NI activity of Pt was higher than that of $\mathrm{Cj}$ except 30-120 days after anthesis (Fig. 4e).

Effect of different rootstocks on the expression of sucrose metabolism-related genes. The expression of the CitSPS1 gene in Pt decreased to the lowest level at 60 days after anthesis and then increased to the highest level at 120 days after anthesis. The expression of the CitSPS1 gene in Pt was higher than that in Cj at all times, except at 30-60 and 300 days after anthesis (Fig. 5a). The CitSPS2 gene of Pt and Cj was almost not expressed until 120 days after anthesis and the maximum expression occurred at 150 days after anthesis in Pt. The CitSPS2 gene expression in Pt was significantly higher than that in $\mathrm{Cj}$ at $150-180$ days after anthesis, but its expression in Pt and Cj showed an opposite trend at 270-300 days after anthesis (Fig. 5b). The expression of the CitSUS in $\mathrm{Cj}$ was low throughout the fruit growth and development processes, and the highest expression occurred at 270 days after anthesis. The expression of this gene in Pt was significantly higher than that in $\mathrm{Cj}$, except at 30-60 and 240 days after anthesis (Fig. 5c). The expression of CUAI1 showed an "M" pattern, reaching its peak at 150 and 285 days after anthesis, and its expression in Pt was significantly higher than that in Cj (Fig. 5d). The CSCW1 gene expression in $\mathrm{Pt}$ and $\mathrm{Cj}$ was the highest at 30 days after anthesis and was then expressed at much lower levels in both rootstocks. Moreover, the CSCW1 gene expression in Pt was always significantly higher than that in $\mathrm{Cj}$ except at 270 days after anthesis (Fig. 5e). CitAI expression in Pt reached the maximum at 120 days after anthesis and reached the second peak at 285 days after anthesis. The expression of this gene in $\mathrm{Cj}$ was very low throughout the fruit growth and development processes (Fig. 5f). NIN expression in Pt initially increased and then decreased, with the highest and lowest expression at 150 and 300 days after anthesis, respectively. Additionally, NIN expression in Pt was higher than that in $\mathrm{Cj}$ at 60 to 285 days after anthesis (Fig. $5 \mathrm{~g}$ ).

Correlation analysis of each index. Correlation analysis of each index is summarised in Table 3 . There was an extremely significant positive correlation between total sugar, sugar components, and SPS activity, whereas titratable acid showed an extremely significant negative correlation with total sugar, sugar components, SPS and NI activities, and CitSPS2 gene expression. The NI activity was extremely significantly positively correlated with the total sugar $(r=0.84)$ and sugar components $(r=0.86,0.81,0.79)$. CitSPS2 expression was positively correlated with the total sugar $(\mathrm{r}=0.54)$, sugar components $(\mathrm{r}=0.54,0.50,0.53)$, and SPS activity $(\mathrm{r}=0.56)$. CSCW1 expression was negatively correlated with the total sugar $(\mathrm{r}=-0.47)$ and sugar components $(\mathrm{r}=-0.48,-0.56$, $-0.52)$, and significant positively correlated with the SS-I activity $(r=0.46)$ and CitSPS1 expression $(r=0.54)$. CitSPS1 expression was positively correlated with the SS-I activity $(r=0.47)$ and NIN expression $(r=0.51)$, but significantly negatively correlated with the SS-II activity $(\mathrm{r}=-0.49)$. CUAI1 expression was extremely significantly positively correlated with the SS-I activity $(\mathrm{r}=0.67)$, and NIN $(\mathrm{r}=0.63)$ and CitSPS1 $(\mathrm{r}=0.56)$ expression, but negatively correlated with the SS-II activity $(\mathrm{r}=-0.50)$. CitAI expression was significant positively correlated 


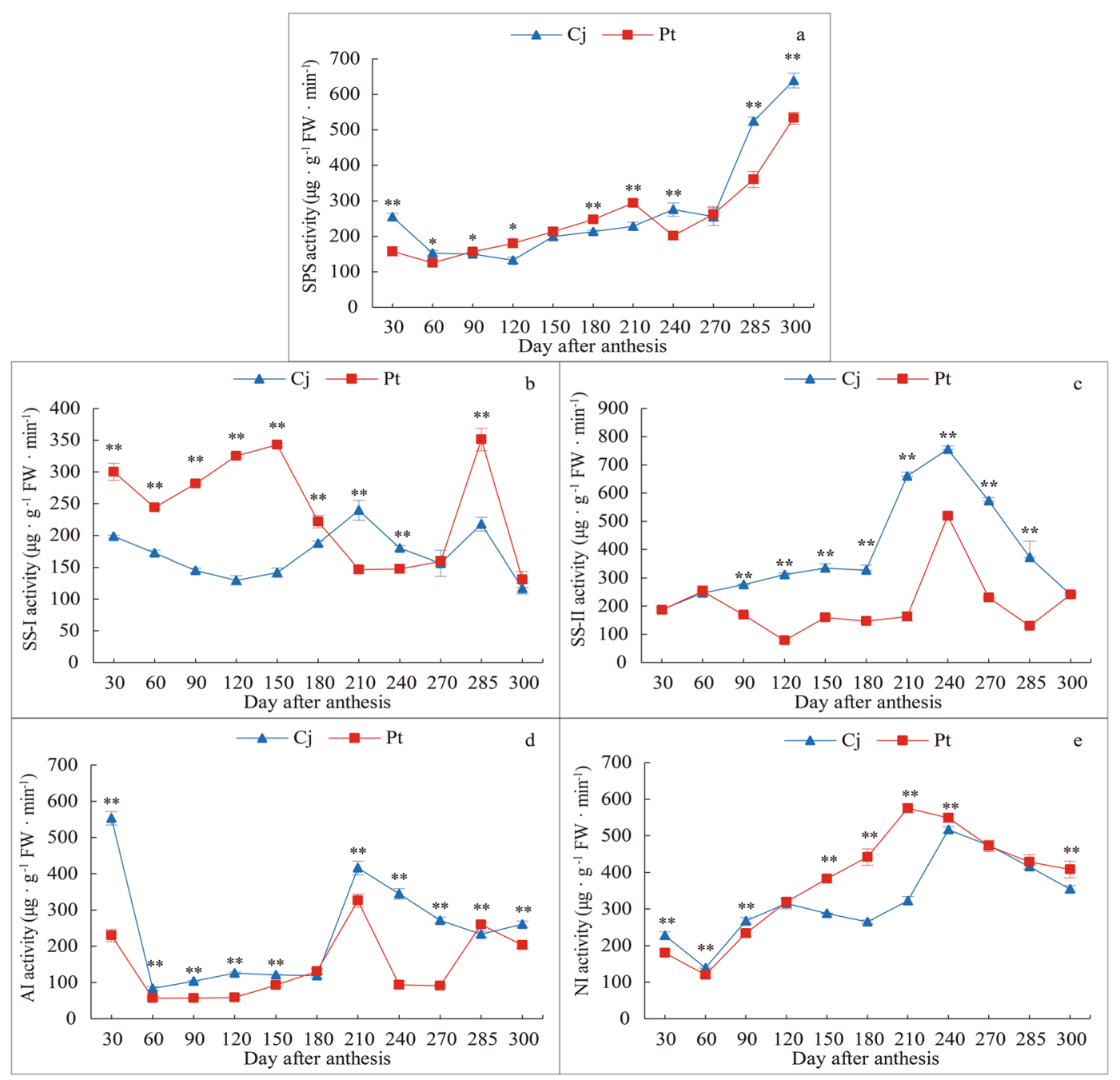

Figure 4. Sucrose metabolism enzyme activities in K. tangor fruit of different rootstocks. (a) SPS activity, (b) SS-I activity, (c) SS-II activity, (d) AI activity, (e) NI activity.

with the SS-I activity $(\mathrm{r}=0.69)$, CitSPS1 $(\mathrm{r}=0.65)$ and CUAII $(\mathrm{r}=0.61)$ expression, but negatively correlated with the SS-II activity $(r=-0.47)$. These correlations can also be visualized in Fig. 6.

\section{Discussion}

There are several methods to determine sugar components by high-performance liquid chromatography globally $^{37}$. We optimised the HPLC method for the determination of sugar components in Citrus, and the Innoval $\mathrm{NH}_{2}$ column used in this analysis has higher application value. The stability, precision, repeatability, and recovery rate of the method used were high (Tables 1 and 2), and this method can therefore be used to effectively determine the content of sugar components in Citrus fruits.

As mentioned previously, sugars determine fruit flavour ${ }^{38}$. This study showed that different rootstocks had a significant effect on sugar accumulation in K. tangor fruit. This was consistent with the results of Killiny et al. ${ }^{39}$. Organic acids play an important role in the flavour and $\mathrm{pH}$ of fruit and affect the sensorial quality of fruits ${ }^{40}$. The sugar content in C j rootstock was significantly lower than that of Pt rootstock, but the difference in acid content was small. Therefore, we focused on the exploration of glucose metabolism. Moreover, there were significant differences in sugar component content, as well as sucrose metabolism enzyme activity and gene expression levels between $\mathrm{Cj}$ and Pt rootstocks (Fig. 6). However, the sugar contents of the two rootstocks were essentially the same at 300 days after anthesis (the ripening stage) (Fig. 2).

Previous studies have reported that the total sugar content and composition are closely related to fruit quality ${ }^{41}$. Sucrose, glucose, and fructose are the major nutritional components of fleshy fruits ${ }^{42}$. Many studies found that sucrose, which was transported through sieve elements and then directly enters into the sink organs through the plasmodesmata or apoplastic space, is the main component for sweetness ${ }^{43,44}$. In accordance with the present study results, sugars in most Citrus fruits, including $K$. tangor, are of the sucrose accumulation type ${ }^{18}$, except in some acidic fruits such as lemons ${ }^{45}$. In this study, sucrose content was the highest, followed by fructose content in the riped $K$. tangor fruit. Moreover, during fruit growth and development, sucrose was accumulated continuously. However, the content of fructose and glucose changed slightly in the later stages of fruit development (Fig. 3), 


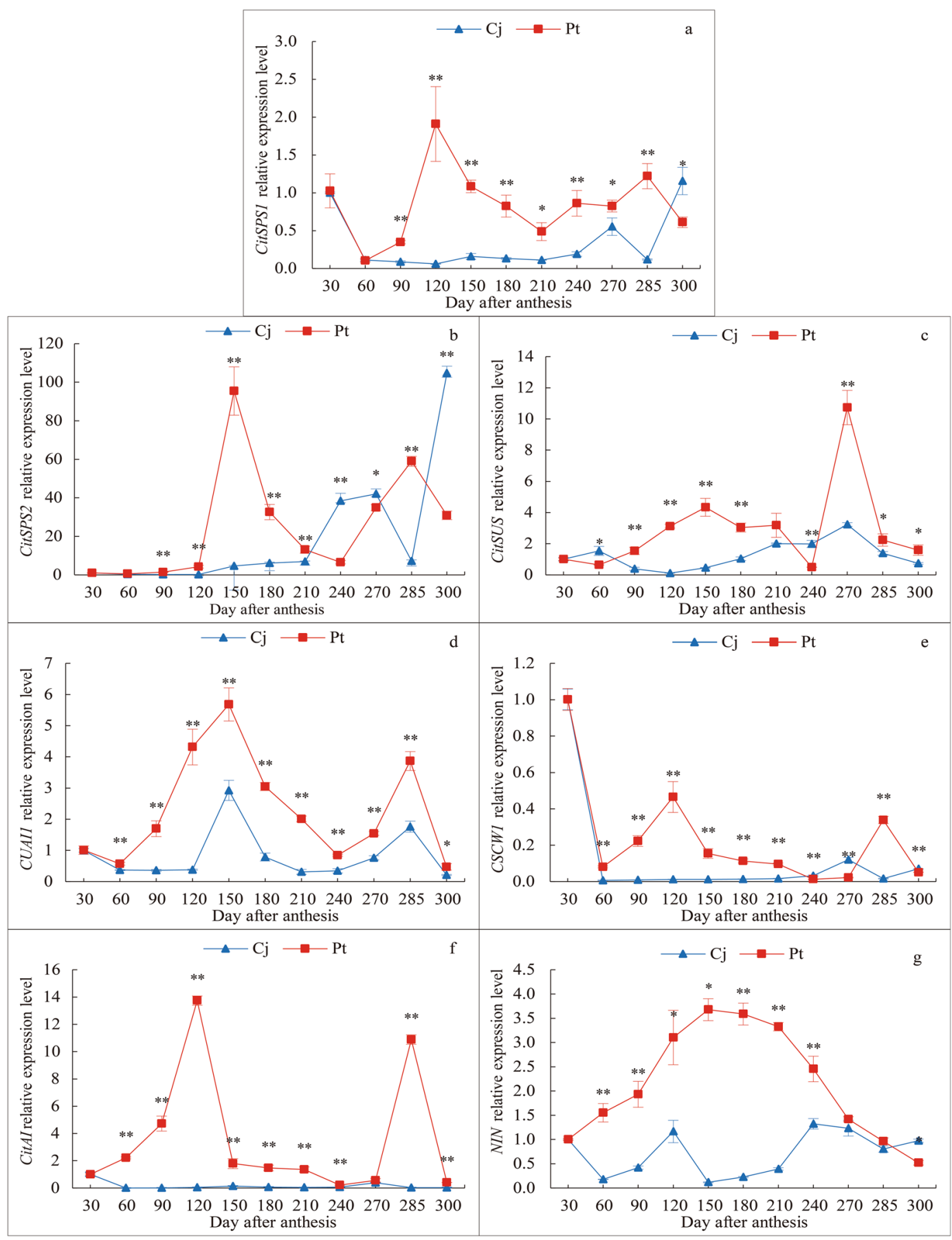

Figure 5. Real-time fluorescence quantitative PCR analysis of the effect of different rootstocks on the relative expression of sucrose metabolism enzyme genes during the growth period of K. tangor. (a) CitSPS1 relative expression level, (b) CitSPS2 relative expression level, (c) CitSUS relative expression level, (d) CUAI1 relative expression level, (e) CSCW1 relative expression level, (f) CitAI relative expression level, (g) NIN relative expression level.

although they also increased continuously in a previous study ${ }^{46}$. This just showed that different rootstocks $(\mathrm{Cj}$ and $\mathrm{Pt}$ ) had an important effect on the accumulation of sugar components in $K$. tangor fruit, especially in the early stage of sugar accumulation.

According to previous studies, sucrose and its main components, glucose, and fructose, are some of the most important sugars in the process of carbon assimilation ${ }^{47}$. The sugar content in $K$. tangor with Pt as a rootstock was higher than that in $K$. tangor with $\mathrm{Cj}$, but there was no significant difference at maturity. Studies have shown that Citrus fructose has the strongest flavour among the sugar components, followed by sucrose ${ }^{48}$. In this study, the content of sucrose and fructose in the fruits of the two rootstocks was significantly different in the later stages of fruit growth and development (240-270 days after anthesis), whereas the content of glucose was only slightly 


\begin{tabular}{|c|c|c|c|c|c|c|c|c|c|c|c|c|c|c|c|c|c|}
\hline & $\begin{array}{l}\text { Total } \\
\text { sugar }\end{array}$ & \begin{tabular}{|l} 
Titratable \\
acid
\end{tabular} & Sucrose & Fructose & Glucose & SPS & SS-I & SS-II & AI & NI & NIN & CitSPS1 & CitSPS2 & CUAII & CitSUS & CSCW1 & CitAI \\
\hline \multicolumn{18}{|l|}{ Total sugar } \\
\hline Titratable acid & $-0.77 * *$ & & & & & & & & & & & & & & & & \\
\hline Sucrose & $0.98^{* * *}$ & $-0.77 * *$ & & & & & & & & & & & & & & & \\
\hline Fructose & $0.93 * *$ & $-0.58^{* *}$ & $0.90^{* *}$ & & & & & & & & & & & & & & \\
\hline Glucose & $0.90^{* *}$ & $-0.56^{* *}$ & $0.87^{* *}$ & $0.99 * *$ & & & & & & & & & & & & & \\
\hline SPS & $0.64^{* *}$ & $-0.63 * *$ & $0.65^{* *}$ & $0.50 *$ & $0.49^{*}$ & & & & & & & & & & & & \\
\hline SS-I & -0.12 & -0.05 & -0.23 & -0.09 & -0.04 & -0.24 & & & & & & & & & & & \\
\hline SS-II & 0.24 & -0.24 & 0.30 & 0.18 & 0.15 & 0.00 & -0.36 & & & & & & & & & & \\
\hline AI & 0.07 & -0.36 & 0.12 & -0.07 & -0.10 & 0.35 & -0.10 & 0.33 & & & & & & & & & \\
\hline $\mathrm{NI}$ & $0.84^{* *}$ & $-0.64 * *$ & $0.86^{* *}$ & $0.81 * *$ & $0.79 * *$ & 0.39 & -0.23 & 0.31 & 0.20 & & & & & & & & \\
\hline NIN & 0.20 & -0.09 & 0.14 & 0.34 & 0.40 & -0.15 & 0.37 & -0.33 & -0.20 & 0.41 & & & & & & & \\
\hline CitSPS1 & 0.17 & -0.36 & 0.15 & 0.17 & 0.24 & 0.19 & $0.47^{*}$ & $-0.49^{*}$ & 0.03 & 0.19 & $0.51^{*}$ & & & & & & \\
\hline CitSPS2 & $0.54^{* *}$ & $-0.54^{*}$ & $0.54^{*}$ & $0.50^{*}$ & $0.53^{*}$ & $0.560 * *$ & 0.11 & -0.07 & 0.09 & 0.39 & 0.28 & $0.43^{*}$ & & & & & \\
\hline CUAI1 & 0.23 & -0.13 & 0.11 & 0.32 & 0.37 & -0.08 & $0.67 * *$ & $-0.50^{*}$ & -0.25 & 0.18 & $0.63^{* *}$ & $0.56^{* *}$ & 0.34 & & & & \\
\hline CitSUS & 0.37 & -0.35 & 0.40 & 0.32 & 0.33 & 0.02 & 0.11 & -0.14 & -0.11 & 0.40 & 0.33 & 0.30 & 0.30 & 0.33 & & & \\
\hline CSCW1 & $-0.47^{*}$ & -0.05 & $-0.48^{*}$ & $-0.56 * *$ & $-0.52^{*}$ & -0.14 & $0.46^{*}$ & -0.38 & \begin{tabular}{|l|l|}
0.40 \\
\end{tabular} & -0.33 & 0.07 & $0.54 * *$ & -0.14 & 0.15 & -0.09 & & \\
\hline CitAI & 0.05 & 0.03 & -0.04 & \begin{tabular}{|l|l}
0.13 \\
\end{tabular} & 0.17 & -0.09 & $0.69^{* * *}$ & $-0.47^{*}$ & -0.18 & -0.02 & 0.33 & $0.65 * *$ & 0.05 & $0.61 * *$ & 0.11 & \begin{tabular}{|l|}
0.31 \\
\end{tabular} & \\
\hline
\end{tabular}

Table 3. Relevance analysis.

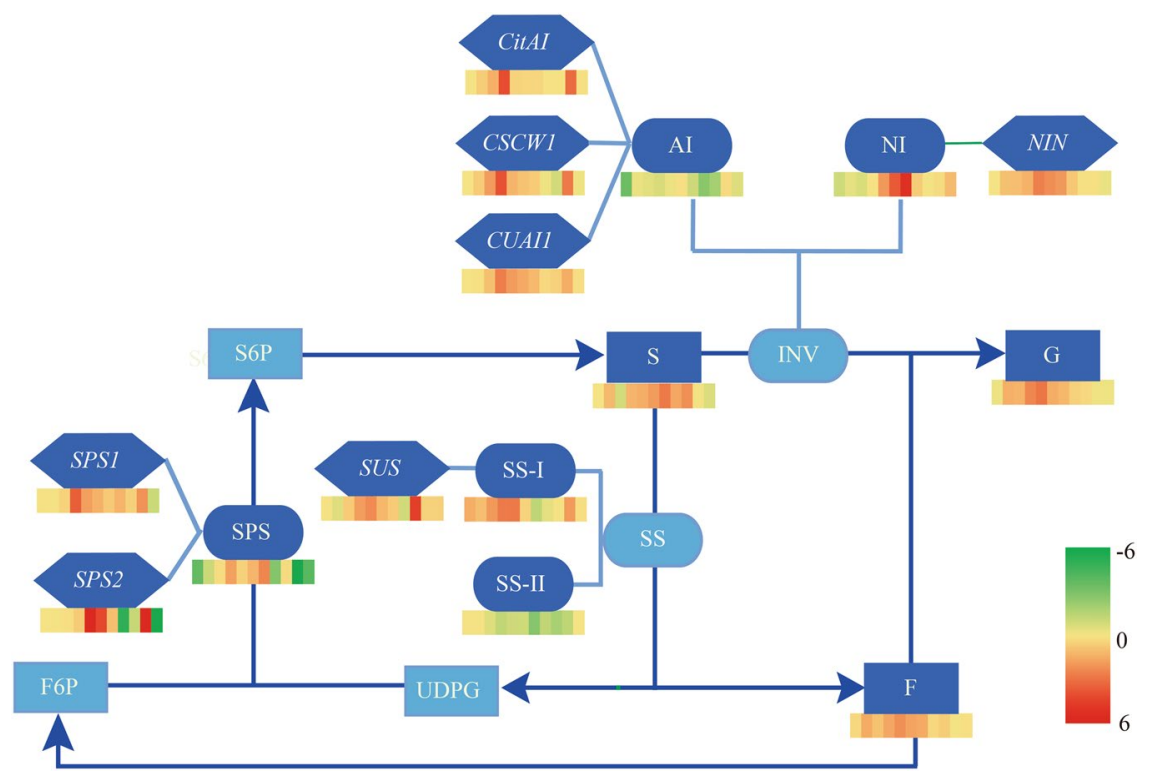

Figure 6. Difference in sugar accumulation between $K$. tangor fruits with $\mathrm{Pt}$ and $\mathrm{Cj}$ as rootstock during fruit growth and maturation. Different colours represent different values of $\frac{X_{P t}-X_{C j}}{\left|\bar{X}_{P t}-X_{C j}\right|}$, and higher values are redder and lower are greener. F presents fructose, $\mathrm{G}$ is glucose, and $\mathrm{S}$ is sucrose.

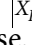

different (Fig. 3), which may be why K. tangor fruits with Ziyang xiangcheng rootstock have a light flavour. Another study found that rootstock regulates sugar metabolism mainly by affecting the content of sucrose and glucose, but there was little effect on fructose content ${ }^{39}$. These results were inconsistent with the conclusion of this study and whether this difference was caused by scion or rootstock remains to be further researched.

Sugar accumulation is an important factor determining fruit quality and sucrose metabolism is important in the regulation of sugar accumulation ${ }^{49-51}$. Furthermore, Citrus SPS plays an important role in sucrose biosynthesis ${ }^{29}$. SS, a sugar accumulation enzyme, determines fruit quality ${ }^{32}$. The correlation analysis showed that SPS was extremely significantly positively correlated with fruit sugar content. This result coincides with the study of Zhang et al. ${ }^{52}$. It was because SPS increased the substrate for sucrose synthesis by producing sucrose-6-phosphate, which in turn increases the content of sucrose. We also found that the SS-II activity of Cj was always higher than that of Pt. Moreover, the SS-I activity of Pt was higher than that of $\mathrm{Cj}$ during the early growth and maturation stages, but it was opposite during the fruit discolouration period. SS-II caused sucrose to break down, and SS-I controls the synthesis of sucrose. Moreover, the NI activity increased with the increase in sugar content (Fig. 4), 
and this phenomenon was consistent with the results of a study on grapes ${ }^{53}$. The increase of NI activity promoted the production of fructose and glucose. In addition, sucrose content decreased after fruit ripening, while fructose and glucose content increased. This suggested that invertase catalysed the irreversible hydrolysis of sucrose into glucose and fructose to maintain the balance of sucrose-sink during fruit growth and development. This further explained the difference in sugar content between the two rootstocks at the level of enzyme activity.

Furthermore, sucrose metabolism enzyme genes affect the sugar content in fruit through the regulation of sucrose metabolism enzymes ${ }^{52,54}$ and seven of these genes were quantitatively analysed in this study. The results showed that for genes related to sugar accumulation or degradation, the expression in Pt was higher than that in $\mathrm{Cj}$, and the expression was essentially the same at the maturity stage for the fruit of both rootstocks (Fig. 5). This result revealed why the sugar content in $\mathrm{Cj}$ rootstock was always lower than that in Pt rootstock at the molecular level. Furthermore, sugar metabolism-related genes of $\mathrm{Pt}$, in which the sugar content was higher, presented relatively higher expression. These results were consistent with the results of Zhu et al. ${ }^{53}$, but differed from the results of Silva ${ }^{55}$ in that the expression levels of SPS1 showed an opposite pattern. Therefore, most of the sucrose metabolizing enzyme activity of Pt was higher, which made its sugar content always higher than $\mathrm{Cj}$.

Before the fruit ripening stage, the sugar content of $\mathrm{Cj}$ rootstock was lower than that of $\mathrm{Pt}$ and the fruit flavour was weak. This was due to the regulation of sucrose metabolism-related enzymes and gene expression. However, 15 to 30 days later, $\mathrm{Cj}$ rootstock increased the expression of sucrose synthesis orientation genes (CitSPS1, CitSPS2), reduced the expression of sucrose decomposition orientation genes (CSCW1, CUAI1), increased the activity of SPS and AI, and reduced the activity of SS-I (the direction of sucrose cleavage) in $K$. tangor fruit. These results therefore indicate that there is no significant difference in the sugar content in K. tangor fruit between the two rootstocks at 30 days after fruit ripening (300 days after anthesis).

\section{Materials and Methods}

Plant materials. Five-year-old K. tangor trees (trifoliate orange and Ziyang xiangcheng were the rootstocks), planted in the Shehong Agricultural Science and Technology Park, were used in this study. There were six K. tangor trees for each of the two rootstocks. All trees were robust, moderately managed, free of pests and diseases, and spaced $3 \mathrm{~m} \times 4 \mathrm{~m}$ apart.

Ten K. tangor fruits from each tree of the two rootstocks were randomly picked every 30 days from 30 to 270 days after anthesis. The fruit was sampled every 15 days after ripening ( 285 and 300 days after anthesis, respectively). Kiyomi tangor fruit peels were then quickly removed and the pulp was cut into small pieces, mixed, and immediately placed on dry ice. Some pulp was taken to the laboratory, and then immediately frozen in liquid nitrogen and stored at $-80^{\circ} \mathrm{C}$ to extract sucrose metabolism enzymes and RNA, and the remaining pulp was placed in a refrigerator at $-20^{\circ} \mathrm{C}$ to determine sugar and acid content.

Total sugar and titratable acid content. TS content in ripe fruit was estimated using the anthrone-sulphuric acid method with minor modifications ${ }^{56}$, while TA content was determined using the He's ${ }^{57}$ method with slightly modification.

Extraction of sugar components. Sugar components were extracted according to the method described by Zhang et al..$^{52}$. Two grams of ground $K$. tangor fruit flesh was mixed with $4 \mathrm{~mL}$ of $\mathrm{H}_{2} \mathrm{O}$ and placed in a water bath at $80^{\circ} \mathrm{C}$ for $15 \mathrm{~min}$. The sample was then centrifuged at $4^{\circ} \mathrm{C}$ for $15 \mathrm{~min}$ at $9000 \mathrm{rpm}$. We then centrifuged the residue again under the same conditions. The resulting supernatant was combined and the volume was fixed to $10 \mathrm{~mL}$. The sample solution was extracted with a disposable syringe and filtered using a $0.45 \mu \mathrm{m}$ hydrophilic membrane into a sample bottle, and then stored at $4{ }^{\circ} \mathrm{C}$ until analysis.

Chromatography conditions and verification of HPLC methodology. Sugar (glucose, fructose, and sucrose) content was analysed by high-performance liquid chromatography (HPLC) (LC-1260; Agilent Technologies, Sacramento, CA, USA) according to the method of Zhang et al. ${ }^{52}$, but we optimised the chromatographic conditions. Samples were isolated on the Innoval $\mathrm{NH}_{2}$ column $(4.6 \mathrm{~mm} \times 250 \mathrm{~mm}, 5 \mu \mathrm{m}$, Agela Technologies, Tianjin, China) at room temperature. The HPLC experiment was completed using a mobile phase (acetonitrile:water $=80: 20(\mathrm{~V} / \mathrm{V})$ ), $20 \mu \mathrm{L}$ sample volume, $1 \mathrm{~mL} \cdot \mathrm{min}^{-1}$ flow rate, $30^{\circ} \mathrm{C}$ column temperature, and $40^{\circ} \mathrm{C}$ detection temperature.

The feasibility of the HPLC method was verified by linear relationship, precision, repeatability, stability, and recovery. The precision, repeatability, stability, and recovery of the samples were tested with reference to the method described by Huang ${ }^{58}$ to analyse the reliability of the treatment method and the chromatographic conditions to determine sugar content in $K$. tangor fruit. The mixed standard solution $\left(2 \mathrm{mg} \cdot \mathrm{mL}^{-1}\right)$ was prepared and sample injection was repeated six times. The standard deviation (RSD) of the standard solution was calculated according to the peak area of each standard sample. The six identical samples were then weighed, the content of sugar components in each sample was calculated according to the peak area, and the RSD values were then calculated. The same sample was then injected at $0,2,4,6,8,12,24,36,48$, and $72 \mathrm{~h}$, respectively, and the RSD values of the sugar content were calculated for the different times. Next, the six samples with known content of sugars were weighed again and a certain amount of the mixed standard solution was added to carry out the recovery experiment.

Determination of sucrose metabolism enzyme activity. Sucrose metabolism enzyme was prepared from frozen tissues of $K$. tangor as described by Zhang ${ }^{44}$. SPS, SS-I, SS-II, AI, and NI activities were assayed using the Plant SPS, SS-I, SS-II, AI, and NI ELISA test kits (Shanghai BOYE Biology Science and Technology Co. Ltd., Shanghai, China) according to the manufacturer's instructions. 


\begin{tabular}{|l|l|l|}
\hline Genes & Primer Forward & Primer Reverse \\
\hline CitSPS1 & GCTCCCTCCTTATCCTTTCGT & AGCAGCAACAAGACATCGAG \\
\hline CitSPS2 & GTTGAACTTGCCCGAGCCTT & ACATCTCGTTCGGTTCACCA \\
\hline CUAI1 & ACAGCTTGGTTGACATCCGAA & ATAAAAGTCCACGCACTCCC \\
\hline CitSUS & AGAGTCACACTGCTTTCACTC & GCTCATATCAGCACCAGGAG \\
\hline CSCW1 & AATAACATCAACGCTAGCTCA & GCGTTTAGCCTTAACCCAGT \\
\hline CitAI & CCTTTCTTCACATCCGCAAT & GCATTGGTTCCAAGGACTTC \\
\hline NIN & CAGCATTACTCTCTGCACGT & TTCCCTGATATGGAATGACAAAG \\
\hline$\beta$-actin & CCAAGCAGCATGAAGATCAA & ATCTGCTGGAAGGTGCTGAG \\
\hline
\end{tabular}

Table 4. Specific primers for quantitative real-time PCR.

Quantitative real-time polymerase chain reaction analysis. Total RNA was extracted from K. tangor fruit of two rootstocks using RNAiso Plus (TaKaRa, Dalian, China). First-strand cDNA was synthesised with using the Prime Script RT reagent Kit with gDNA Eraser (Takara, Dalian, China) ${ }^{26}$. Primer 3.0 online tool (http:// bioinfo.ut.ee/primer3-0.4.0/) was used to design primers, which were synthesised by Sangon Biotech, China. Primer sequences of the CitSPS1, CitSPS2, CUAI1, CitSUS, CSCW1, CitAI, NIN, and $\beta$-actin gene were listed in Table 4 . The quantitative real-time polymerase chain reaction (qRT-PCR) experiment was conducted using SYBR Premix Ex Taq II (Takara, Dalian, China) and the CFX96 Real-Time PCR system (Bio-Rad, California) with three technical replicates ${ }^{59}$. All primers were amplified with no template control to ensure the amplicons were not primer dimers. The relative gene expression levels were calculated using the $2^{-\Delta \Delta \mathrm{CT}}$ method with the $\beta$-actin gene serving as the internal control ${ }^{60}$.

Data analysis. The data were analysed with Statistic, version 23.0 of IBM SPSS. Statistically significant differences $(\mathrm{p}<0.05)$ and extremely significant differences $(\mathrm{p}<0.01)$ between the treatments were revealed after independent sample t-test graphs were plotted using Adobe Illustrator and SigmaPlot 12.5 .

Received: 21 June 2019; Accepted: 30 November 2019;

Published online: 17 December 2019

\section{References}

1. Biswas, M. K., Chai, L., Amar, M. H., Zhang, X. \& Deng, X. Comparative analysis of genetic diversity in Citrus germplasm collection using AFLP, SSAP, SAMPL and SSR markers. Scientia Horticulturae 129, 798-803, https://doi.org/10.1016/j.scienta.2011.06.015 (2011).

2. Xiong, B. et al. Transcriptome Analyses of Two Citrus Cultivars (Shiranuhi and Huangguogan) in Seedling Etiolation. Scientific reports 7, 46245, https://doi.org/10.1038/srep46245 (2017).

3. Han, S., Kim, H. M. \& Lee, S. Simultaneous determination of polymethoxyflavones in Citrus species, Kiyomi tangor and Satsuma mandarin, by high performance liquid chromatography. Food chemistry 134, 1220-1224, https://doi.org/10.1016/j. foodchem.2012.02.187 (2012).

4. Chang, Y. H. et al. Bioconverted Jeju Hallabong tangor (Citrus kiyomi x ponkan) peel extracts by cytolase enhance antioxidant and anti-inflammatory capacity in RAW 264.7 cells. Nutrition research and practice 10, 131-138, https://doi.org/10.4162/ nrp.2016.10.2.131 (2016).

5. Wu, X. et al. Boron Deficiency in Trifoliate Orange Induces Changes in Pectin Composition and Architecture of Components in Root Cell Walls. Frontiers in plant science 8, 1882, https://doi.org/10.3389/fpls.2017.01882 (2017).

6. Tan, F. Q. et al. Comparative metabolic and transcriptional analysis of a doubled diploid and its diploid citrus rootstock (C. junos cv. Ziyang xiangcheng) suggests its potential value for stress resistance improvement. BMC plant biology 15, 89, https://doi.org/10.1186/ s12870-015-0450-4 (2015).

7. Gong, X. \& Liu, J. Genetic transformation and genes for resistance to abiotic and biotic stresses inCitrusand its related genera. Plant Cell, Tissue and Organ Culture 113, 137-147, https://doi.org/10.1007/s11240-012-0267-x (2013).

8. Castle, W. S. Rootstock as a fruit quality factor in citrus and deciduous tree crops. New Zealand Journal of Crop and Horticultural Science 23, 383-394, https://doi.org/10.1080/01140671.1995.9513914 (1995).

9. Zhou, G. F. et al. Transcription profiles of boron-deficiency-responsive genes in citrus rootstock root by suppression subtractive hybridization and cDNA microarray. Frontiers in plant science 5, 795, https://doi.org/10.3389/fpls.2014.00795 (2014).

10. Wu, J. et al. Genome-wide comprehensive analysis of transcriptomes and small RNAs offers insights into the molecular mechanism of alkaline stress tolerance in a citrus rootstock. Horticulture research 6, 33, https://doi.org/10.1038/s41438-018-0116-0 (2019).

11. Xiong, B. et al. Variability in CitXET expression and XET activity in Citrus cultivar Huangguogan seedlings with differed degrees of etiolation. PloS one 12, e0178973, https://doi.org/10.1371/journal.pone.0178973 (2017).

12. Zhou, G. F. et al. The physiological and nutritional responses of seven different citrus rootstock seedlings to boron deficiency. Trees 28, 295-307, https://doi.org/10.1007/s00468-013-0949-y (2014).

13. Liu, Y., Liu, Q., Xiong, J. \& Deng, X. Difference of a citrus late-ripening mutant (Citrus sinensis) from its parental line in sugar and acid metabolism at the fruit ripening stage. Science in China. Series C, Life sciences/Chinese Academy of Sciences 50, 511-517, https:// doi.org/10.1007/s11427-007-0063-8 (2007).

14. Komatsu, A., Moriguchi, T., Koyama, K., Omura, M. \& Akihama, T. Analysis of sucrose synthase genes in citrus suggests different roles and phylogenetic relationships. Journal of experimental botany 53,61-71 (2002).

15. Dai, Z. et al. Inter-Species Comparative Analysis of Components of Soluble Sugar Concentration in Fleshy Fruits. Frontiers in plant science 7, 649, https://doi.org/10.3389/fpls.2016.00649 (2016)

16. YL, R. Sucrose metabolism: gateway to diverse carbon use and sugar signaling. Annual review of plant biology 65, 33-67 (2014).

17. Wang, L. et al. Glycine betaine reduces chilling injury in peach fruit by enhancing phenolic and sugar metabolisms. Food chemistry 272, 530-538, https://doi.org/10.1016/j.foodchem.2018.08.085 (2019).

18. Lin, Q. et al. Transcriptome and metabolome analyses of sugar and organic acid metabolism in Ponkan (Citrus reticulata) fruit during fruit maturation. Gene 554, 64-74, https://doi.org/10.1016/j.gene.2014.10.025 (2015).

19. Guo, J., Jermyn, W. A. \& Turnbull, M. H. Carbon assimilation, partitioning and export in mature cladophylls of two asparagus (Asparagus officinalis) cultivars with contrasting yield. Physiologia plantarum 115, 362-369 (2002). 
20. Huber, S. C. \& Huber, J. L. Role and Regulation Of Sucrose-Phosphate Synthase in Higher Plants. Annual review of plant physiology and plant molecular biology 47, 431-444 (1996).

21. Zhu, A. et al. Microarray expression profiling of postharvest Ponkan mandarin (Citrus reticulata) fruit under cold storage reveals regulatory gene candidates and implications on soluble sugars metabolism. J Integr Plant Biol 53, 358-374, https://doi.org/10.1111/ j.1744-7909.2011.01035.x (2011).

22. Koch, K. Sucrose metabolism: regulatory mechanisms and pivotal roles in sugar sensing and plant development. Current opinion in plant biology 7, 235-246, https://doi.org/10.1016/j.pbi.2004.03.014 (2004).

23. Burger, Y. \& Schaffer, A. A. The contribution of sucrose metabolism enzymes to sucrose accumulation in Cucumis melo. Journal of the American Society for Horticultural Science 132, 704-712, https://doi.org/10.21273/JASHS.132.5.704 (2019).

24. Roitsch, T. \& Gonzalez, M. C. Function and regulation of plant invertases: sweet sensations. Trends in plant science 9, 606-613, https://doi.org/10.1016/j.tplants.2004.10.009 (2004).

25. Wan, H., Wu, L., Yang, Y., Zhou, G. \& Ruan, Y. L. Evolution of Sucrose Metabolism: The Dichotomy of Invertases and Beyond. Trends in plant science 23, 163-177 (2018).

26. Dahro, B., Wang, F., Peng, T. \& Liu, J. H. PtrA/NINV, an alkaline/neutral invertase gene of Poncirus trifoliata, confers enhanced tolerance to multiple abiotic stresses by modulating ROS levels and maintaining photosynthetic efficiency. BMC plant biology 16, 76, https://doi.org/10.1186/s12870-016-0761-0 (2016).

27. Kubo, T., Hohjo, I. \& Hiratsuka, S. Sucrose accumulation and its related enzyme activities in the juice sacs of satsuma mandarin fruit from trees with different crop loads. Scientia Horticulturae 91, 215-225, https://doi.org/10.1016/S0304-4238(01)00262-X (2001).

28. Ge, Y. et al. Changes in the sucrose metabolism in apple fruit following postharvest acibenzolar-S-methyl treatment. Journal of the science of food and agriculture 99, 1519-1524, https://doi.org/10.1002/jsfa.9326 (2019).

29. Zhu, S. et al. Changes in sugar content and related enzyme activities in table grape (Vitis vinifera L.) in response to foliar selenium fertilizer. Journal of the science of food and agriculture 97, 4094-4102, https://doi.org/10.1002/jsfa.8276 (2017).

30. Degu, A. et al. Metabolite and transcript profiling of berry skin during fruit development elucidates differential regulation between Cabernet Sauvignon and Shiraz cultivars at branching points in the polyphenol pathway. BMC plant biology 14, 188, https://doi. org/10.1186/s12870-014-0188-4 (2014).

31. Komatsu, A., Takanokura, Y., Omura, M. \& Akihama, T. Cloning and molecular analysis of cDNAs encoding three sucrose phosphate synthase isoforms from a citrus fruit (Citrus unshiu Marc.). Molecular \& general genetics: MGG 252, 346-351 (1996).

32. Islam, M. Z., Hu, X. M., Jin, L. F., Liu, Y. Z. \& Peng, S. A. Genome-wide identification and expression profile analysis of citrus sucrose synthase genes: investigation of possible roles in the regulation of sugar accumulation. PloS one 9, e113623, https://doi.org/10.1371/ journal.pone.0113623 (2014).

33. Kou, J. et al. Infection of post-harvest peaches by Monilinia fructicola accelerates sucrose decomposition and stimulates the Embden-Meyerhof-Parnas pathway. Horticulture research 5, 46, https://doi.org/10.1038/s41438-018-0046-x (2018).

34. Wu, Y. et al. Effect of Candidatus Liberibacter asiaticus Infection on Carbohydrate Metabolism in Citrus sinensis. Scientia Agricultura Sinica 48, 63-72, https://doi.org/10.3864/j.issn.0578-1752.2015.01.07 (2015).

35. Liu, Y., Liu, Q., Xiong, J. \& Deng, X. Difference of a citrus late-ripening mutant (Citrus sinensis) from its parental line in sugar and acid metabolism at the fruit ripening stage. Science in China Series C-Life Sciences 50, 511-517, https://doi.org/10.1007/s11427-0070063-8 (2007).

36. Jin, W.-W., Chen, G., Zhu, J. \& Gao, A. Gene clone, sequence analysis and gene expression of NIN and Sus from Ougan fruit. Acta Agriculturae Zhejiangensis 28, 782-789, 10. 3969/j.issn. 1004-1524. 2016. 05. 12 (2016).

37. Kelebek, H. \& Selli, S. Determination of volatile, phenolic, organic acid and sugar components in a Turkish cv. Dortyol (Citrus sinensis L. Osbeck) orange juice. Journal of the science of food and agriculture 91, 1855-1862, https://doi.org/10.1002/jsfa.4396 (2011).

38. Ornelas-Paz Jde, J. et al. Physical attributes and chemical composition of organic strawberry fruit (Fragaria $\mathrm{x}$ ananassa Duch, Cv. Albion) at six stages of ripening. Food chemistry 138, 372-381, https://doi.org/10.1016/j.foodchem.2012.11.006 (2013).

39. Killiny, N., Valim, M. F., Jones, S. E. \& Hijaz, F. Effect of different rootstocks on the leaf metabolite profile of 'Sugar Belle' mandarin hybrid. Plant signaling \& behavior 13, e1445934, https://doi.org/10.1080/15592324.2018.1445934 (2018).

40. Montero, T. M., Mollá, E., Esteban, R. M. \& López-Andréu, F. J. Quality attributes of strawberry during ripening. Scientia Horticulturae 65, 239-250, https://doi.org/10.1016/0304-4238(96)00892-8 (1996).

41. Keutgen, A. J. \& Pawelzik, E. Quality and nutritional value of strawberry fruit under long term salt stress. Food chemistry 107, 1413-1420, https://doi.org/10.1016/j.foodchem.2007.09.071 (2008).

42. Zhang, C., Bian, Y., Hou, S. \& Li, X. Sugar transport played a more important role than sugar biosynthesis in fruit sugar accumulation during Chinese jujube domestication. Planta 248, 1187-1199, https://doi.org/10.1007/s00425-018-2971-1 (2018).

43. Pressman, E., Shaked, R., Shen, S., Altahan, L. \& Firon, N. Variations in Carbohydrate Content and Sucrose-Metabolizing Enzymes in Tomato (Solanum lycopersicum L.) Stamen Parts during Pollen Maturation. American Journal of Plant Sciences 3, 252-260, https://doi.org/10.4236/ajps.2012.32030 (2012).

44. Zhang, X. M. et al. Dynamic analysis of sugar metabolism in different harvest seasons of pineapple (Ananas comosus L.(Merr.)). African Journal of Biotechnology 10, 2716-2723, https://doi.org/10.5897/AJB10.1284 (2011).

45. Albertini, M. V. et al. Changes in organic acids and sugars during early stages of development of acidic and acidless citrus fruit. $J$ Agric Food Chem 54, 8335-8339, https://doi.org/10.1021/jf061648j (2006).

46. Zhou, Y. et al. Fruit sugar and organic acid were significantly related to fruit Mg of six citrus cultivars. Food Chem 259, 278-285, https://doi.org/10.1016/j.foodchem.2018.03.102 (2018).

47. Akihiro, I. \& Takuro, T. Inhibition of sucrose loss during cold storage in Japanese pear (Pyrus pyrifolia Nakai) by 1-MCP. Postharvest biology and technology 48, 355-363, https://doi.org/10.1016/j.postharvbio.2007.10.015 (2008).

48. Vranes, M. B. et al. The solvation properties and effect of $\mathrm{d}$-fructose on the taste behavior of Citrus aurantium active components in aqueous solutions. Food \& function 9, 5569-5579, https://doi.org/10.1039/c8fo01088a (2018).

49. Wang, L. et al. Identification of candidate genes involved in the sugar metabolism and accumulation during pear fruit post-harvest ripening of 'Red Clapp's Favorite' (Pyrus communis L.) by transcriptome analysis. Hereditas 155, 11, https://doi.org/10.1186/s41065017-0046-0 (2018).

50. Vincent, B. et al. The venom composition of the parasitic wasp Chelonus inanitus resolved by combined expressed sequence tags analysis and proteomic approach. BMC genomics 11, 693, https://doi.org/10.1186/1471-2164-11-693 (2010).

51. Tanase, K., Shiratake, K., Mori, H. \& Yamaki, S. Changes in the phosphorylation state of sucrose synthase during development of Japanese pear fruit. Physiologia plantarum 114, 21-26 (2002).

52. Zhang, X. M. et al. Expression patterns, activities and carbohydrate-metabolizing regulation of sucrose phosphate synthase, sucrose synthase and neutral invertase in pineapple fruit during development and ripening. Int J Mol Sci 13, 9460-9477, https://doi. org/10.3390/ijms13089460 (2012).

53. Zhu, X. et al. Enzyme activities and gene expression of starch metabolism provide insights into grape berry development. Hortic Res 4, 17018, https://doi.org/10.1038/hortres.2017.18 (2017).

54. Blee, K. A. \& Anderson, A. J. Transcripts for genes encoding soluble acid invertase and sucrose synthase accumulate in root tip and cortical cells containing mycorrhizal arbuscules. Plant molecular biology 50, 197-211 (2002). 
55. Silva, A., Noronha, H., Dai, Z., Delrot, S. \& Geros, H. Low source-sink ratio reduces reserve starch in grapevine woody canes and modulates sugar transport and metabolism at transcriptional and enzyme activity levels. Planta 246, 525-535, https://doi. org/10.1007/s00425-017-2708-6 (2017).

56. Zeng, J. et al. Composition and aggregation of extracellular polymeric substances (EPS) in hyperhaline and municipal wastewater treatment plants. Scientific reports 6, 26721, https://doi.org/10.1038/srep26721 (2016).

57. He, Y. et al. Pre-Harvest Treatment of Chitosan Oligosaccharides Improved Strawberry Fruit Quality. International journal of molecular sciences 19, https://doi.org/10.3390/ijms19082194 (2018).

58. Huang, S. et al. Variation in limonin and nomilin content in citrus fruits of eight varieties determined by modified HPLC. Food Sci Biotechnol 28, 641-647, https://doi.org/10.1007/s10068-018-0509-8 (2019).

59. Huang, D., Zhao, Y., Cao, M., Qiao, L. \& Zheng, Z. L. Integrated Systems Biology Analysis of Transcriptomes Reveals Candidate Genes for Acidity Control in Developing Fruits of Sweet Orange (Citrus sinensis L. Osbeck). Frontiers in plant science 7,486 (2016).

60. Silva, A., Noronha, H., Dai, Z., Delrot, S. \& Gerós, H. Low source-sink ratio reduces reserve starch in grapevine woody canes and modulates sugar transport and metabolism at transcriptional and enzyme activity levels. Planta 246, 525-535 (2017).

\section{Acknowledgements}

This research was funded by grants: 2019NZZJ0013 (to B.X.) and 2016NZ0056 (to Z.-H.W.) from The Science and Technology Department of Sichuan Province, China.

\section{Author contributions}

T.-T.D., B.X. and Z.-H.W. conceived and designed the experiments. T.-T.D., B.X., S.-J.H., X.-J.W. and X.Z. carried out the experiments. L.L., S.-C.L. and X.Q. analysed the data. Y.-Z.-Z.H., C.-W.D. and J.Z. contributed to samples collection. T.-T.D. and B.X. wrote the paper. Z.-H.W. and G.-C.S. revised the manuscript. All authors approved the final revision to be published. T.-T.D. and B.X. contributed equally to this work.

\section{Competing interests}

The authors declare no competing interests.

\section{Additional information}

Supplementary information is available for this paper at https://doi.org/10.1038/s41598-019-55957-3.

Correspondence and requests for materials should be addressed to Z.W.

Reprints and permissions information is available at www.nature.com/reprints.

Publisher's note Springer Nature remains neutral with regard to jurisdictional claims in published maps and institutional affiliations.

(c) Open Access This article is licensed under a Creative Commons Attribution 4.0 International License, which permits use, sharing, adaptation, distribution and reproduction in any medium or format, as long as you give appropriate credit to the original author(s) and the source, provide a link to the Creative Commons license, and indicate if changes were made. The images or other third party material in this article are included in the article's Creative Commons license, unless indicated otherwise in a credit line to the material. If material is not included in the article's Creative Commons license and your intended use is not permitted by statutory regulation or exceeds the permitted use, you will need to obtain permission directly from the copyright holder. To view a copy of this license, visit http://creativecommons.org/licenses/by/4.0/.

(C) The Author(s) 2019 